\title{
Spatio-temporal Variability in Sea Surface Temperatures for the Yellow Sea based on MODIS Dataset
}

\author{
Chunli Liu ${ }^{1}$, Qiwei Sun ${ }^{2,3}$, Qianguo Xing ${ }^{4}$, Zhenlin Liang ${ }^{1}$, Yue Deng ${ }^{1 *}$, and Lixin Zhu ${ }^{1}$ \\ ${ }^{1}$ Marine College, Shandong University, Weihai 264209, China \\ ${ }^{2}$ The State Key Laboratory of Tropical Oceanography, South China Sea Institute of Oceanology, Chinese Academy of Sciences, Guangzhou \\ 510301, China \\ ${ }^{3}$ University of Chinese Academy of Sciences, Beijing 100049, China \\ ${ }^{4}$ Yantai Institute of Coastal Zone Research, Chinese Academy of Sciences, Yantai 264003, China
}

Received 26 July 2016; Revised 23 October 2016; Accepted 6 December 2016

(c) KSO, KIOST and Springer 2017

\begin{abstract}
The spatio-temporal variabilities in sea surface temperature (SST) were analyzed using a time series of MODIS datasets for four separate regions in the Yellow Sea (YS) that were located along a north-south axis. The space variant temporal anomaly was further decomposed using an empirical orthogonal function (EOF) for estimating spatially distributed SST. The monthly SSTs showed similar temporal patterns in each region, which ranged from $2.4^{\circ} \mathrm{C}$ to $28.4^{\circ} \mathrm{C}$ in the study years 2011 to 2013 , with seasonal cycles being stronger at the higher latitudes and weaker at the lower latitudes. Spatially, although there were no significant differences among the four regions $(p<0.05)$ in any year, the geographical distribution of SST was characterized by an obvious gradient whereby SST decreased along the north-south axis. The monthly thermal difference among regions was largest in winter since the SST in the southeast was mainly affected by the Yellow Sea Warm Currents. The EOF 1 mode accounted for $56 \%$ of the total spatial variance and exhibited a warming signal during the study period. The EOF2 mode accounted for $8 \%$ of the total variance and indicated the warm current features in the YS. The EOF3 mode accounted for $6 \%$ of the total variance and indicated the topographical features. The methodology used in this study demonstrated the spatiotemporal variabilities in the YS.
\end{abstract}

Key words - Yellow Sea, sea surface temperature, currents, empirical orthogonal function analysis

\section{Introduction}

The Yellow Sea (YS) is a semi-enclosed marginal sea that has a mean water depth of $44 \mathrm{~m}$. There is a north-south oriented trough ( $>70 \mathrm{~m}$ deep) in the central area, and the

\footnotetext{
*Corresponding author. E-mail: dengyuedy@163.com
}

bathymetric contours on both sides of the trough are generally parallel to the coastline (Fig. 1). During winter (DecemberFebruary), the Yellow Sea Warm Current (YSWC) enters the YS from the southeast and advances to the north (Teague and Jacobs 2000; Lie et al. 2009; Yu et al. 2010) and the Yellow Sea Cold Water Mass (YSCWM; $122^{\circ}-125^{\circ} \mathrm{E}, 34^{\circ}-$ $37^{\circ} \mathrm{N}$ ) becomes entrenched at the bottom of the sea during the summer (June-August) (Ho et al. 1959; Yu et al. 2006; Zhang et al. 2008; Mei et al. 2016). These water masses represent the two most important physical oceanographic features in the YS. In addition, a southward coastal flow is present during winter along the eastern and western boundaries of the YS (Uda 1934, 1936) and corresponds to the development of the northward YSWC in the central sea area (Wei et al. 2016; Xu et al. 2016).

Sea Surface Temperature (SST) is one of the more important oceanic and atmospheric variables and has been widely used in a variety of studies intended to develop an understanding of ocean dynamics, as well as of the physical and biogeochemical processes occurring in the upper layers of the sea. The importance of SST variability in the YS has been addressed by numerous satellite-based studies (Lin et al. 2005; Shi and Wang 2012; Tseng et al. 2000; Wei et al. 2010; Yeh and Kim 2010). This literature also reports that the complex spatial and temporal variabilities in SST are associated with features such as the thermal or tidal fronts, coastal waters, and currents, etc. that are described above. Recently, several analyses of SST datasets have considered the spatial and temporal distributions of SST in order to examine seasonal and annual SST variability 
and the warming signal in the YS. These studies used the empirical orthogonal function (EOF) method (Yeh and Kim 2010; Park et al. 2015), which is also widely used in other disciplines (Alvarez and Pan 2016; Hu and Si 2016). These earlier studies of SST variability consider the YS as an area in its entirety and focus on relatively long time series variations. The SST exhibits strong variabilities since it is affected greatly by the heterogeneity of hydrographic features in the YS described above. In contrast, in this present study, we seek to compare detailed spatio-temporal patterns of SST in the YS by investigating several separate regions of the YS over a relatively short time-scale.

Therefore, we carried out such an investigation that utilized a time series of SST datasets obtained from the Moderate Resolution Imaging Spectroradiometer (MODIS) sensor onboard the Aqua satellite of NASA. We compared the differences in spatial and temporal variabilities for four separate geographical regions in the YS and examined the relation between SST and the regional processes reported by Park et al. (2015) by using the EOF analysis method. The main objectives of this study were to (1) compare the spatial and temporal patterns of the SST in the four regions and (2) investigate the spatial patterns of dominant temporal SST variability by EOF decomposition in the study area.

\section{Data Source and Methods}

\section{Data source}

The MODIS level-3 thermal Infra-red (TIR) (11 micron) daytime monthly composites SST measured by the Aqua satellite of NASA for the years 2011-2013 were downloaded from the ocean color website (http://oceancolor.gsfc.nasa.gov/cgi/ 13) and processed at $4 \mathrm{~km}$ resolution based on the algorithm theory of Brown and Minnett (1999). In order to examine spatial and temporal differences in SST variability from the northern to the southern boundaries of the YS, we defined four separate regions lying along a north to south axis (Fig. 1). The exact positions of these regions were all located in the central part of the YS as related to its western and eastern boundaries, since the SSTs in coastal waters are affected greatly by discharge from rivers and other water sources (Park et al. 2015). The area of each region was bounded by a rectangle ( 2 by 1 ) oriented along a west to east axis. The four regions were designated as Regions 1 to 4 and the upper left corners of these regions had the following geographical coordinates: Region $1,122^{\circ} \mathrm{E}$ and $39^{\circ} \mathrm{N}$; Region 2: $123^{\circ} \mathrm{E}$

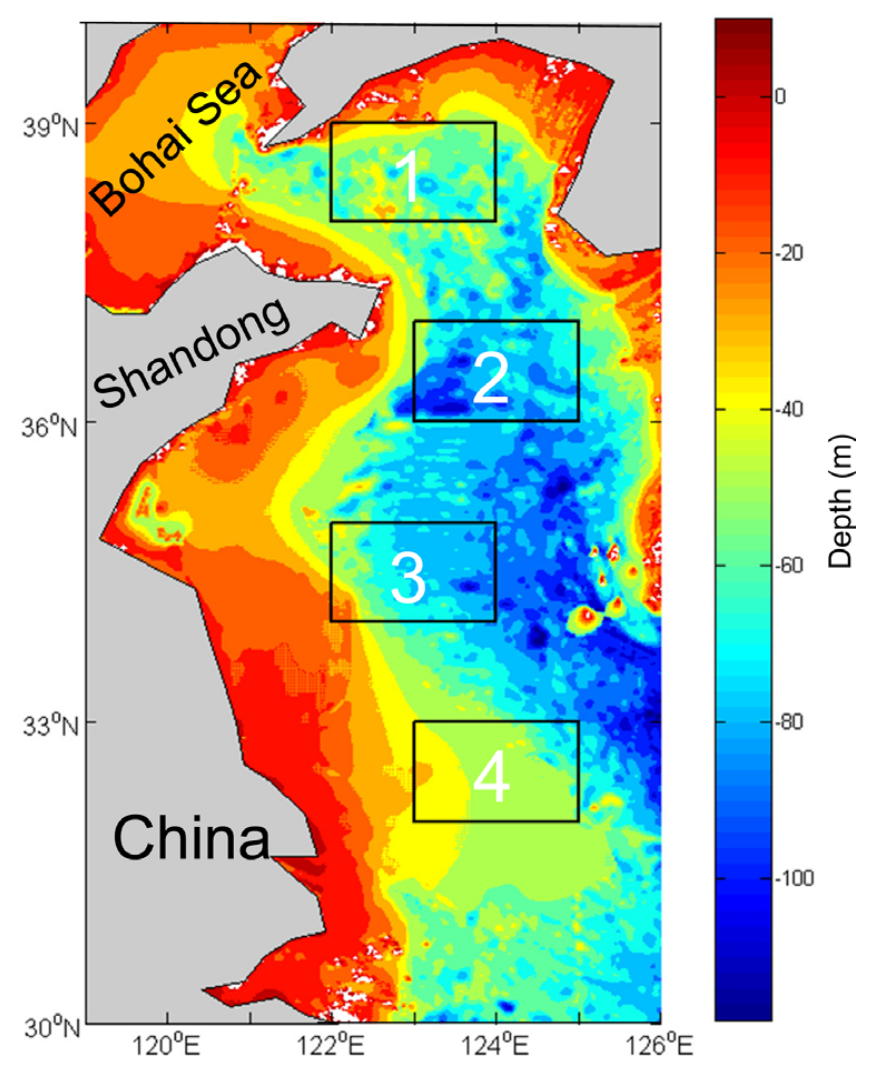

Fig. 1. Study area with four defined geographic regions (numbered rectangles) in the Yellow Sea

and $37^{\circ} \mathrm{N}$; Region $3: 122^{\circ} \mathrm{E}$ and $35^{\circ} \mathrm{N}$; and Region $4: 123^{\circ} \mathrm{E}$ and $33^{\circ} \mathrm{N}$.

\section{Empirical orthogonal function (EOF) analysis}

To simplify and quantify the complex variability in the monthly SST from 2011 to 2013 throughout the YS, the spatial SST datasets were decomposed into their dominant modes using EOF analysis (Kelly 1988; Lagerloefand Bernstein 1988). Since the input map time series should not have missing data in order to conduct the EOF analysis, we first used the monthly SST datasets that had the fewest number of pixels without data (due to cloud cover, etc.) in the study area. Then, for the pixels where data was missing, data was inserted based on an interpolation that used the mean of the valid measured SST values of the time series.

All of the SST datasets were adjusted by removing the temporal average of the 36 monthly datasets. This was expressed as:

$$
I^{\prime}(x, t)=I(x, t)-\frac{1}{N} \sum_{t=1}^{N} I(x, t)
$$


where $I^{\prime}(x, t)$ is the set of all adjusted monthly datasets, $I(x, t)$ represents the set of all monthly datasets; and $N$ is the number of all monthly datasets. Using EOF analysis, the 36 adjusted monthly datasets produced the temporal variance.

Alternatively, the spatial average of each monthly dataset was removed as follows:

$$
I^{\prime}(x, t)=I(x, t)-\frac{1}{M} \sum_{x=1}^{M} I(x, t)
$$

where $M$ is the total number of pixels of each dataset. The spatial variance could then be examined using the EOF analysis.

The spatially or temporally adjusted $I^{\prime}(x, t)$ datasets were used to calculate the autovariance of each dataset and the covariance between datasets. An eigenvector $a_{n}(t)$ was then obtained to decompose $I^{\prime}(x, t)$ as follows:

$$
I^{\prime}(x, t)=\sum_{n=1}^{N} a_{n} F_{n}(x)
$$

The time-varying amplitude function, $a_{n}(t)$, was calculated by the projection method using the formula:

$$
a_{n}(t)=\sum_{t=1}^{M} I^{\prime}(x, t) F_{n}(x)
$$

In Eqs. (3) and (4), $F_{n}(x)$ is the spatial amplitude function
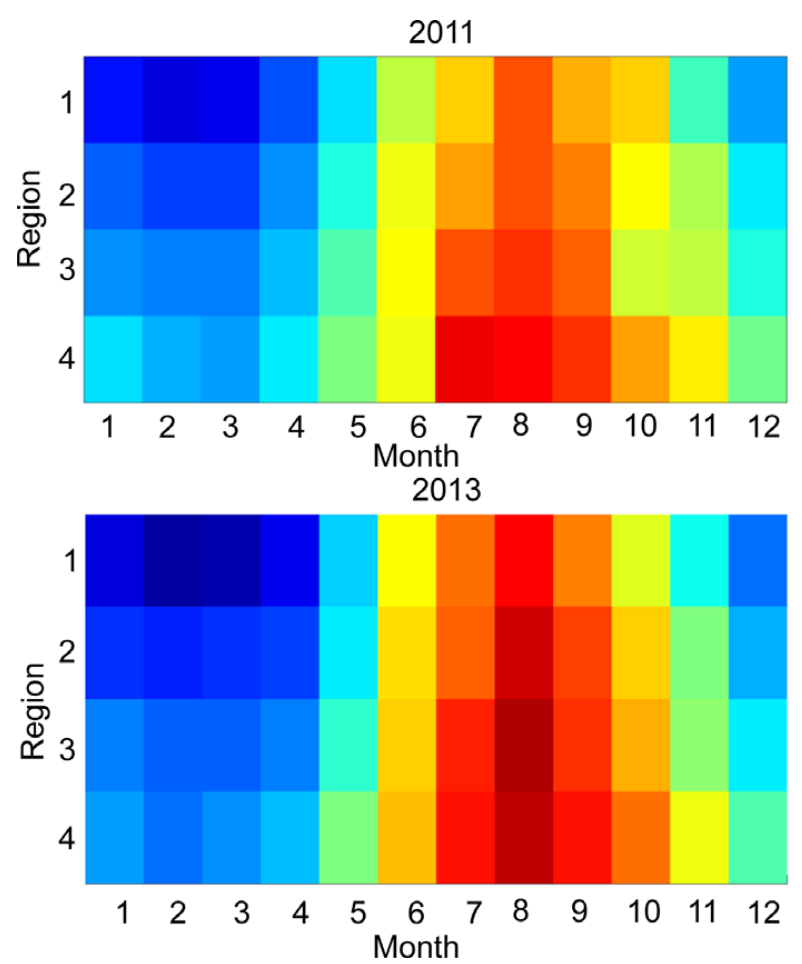

Fig. 2. Monthly temporal distributions of SST $\left({ }^{\circ} \mathrm{C}\right)$ in the four study regions of each EOF mode that was used to make a comparison of the dominant hydrographic distribution patterns in the YS.

In order to test the significance of the EOF modes, we used the methods described by North et al. (1982). The error produced in a given $\operatorname{EOF}\left(e_{j}\right)$ was calculated as:

$$
e_{j}=\lambda_{j}\left(\frac{2}{N}\right)^{0.5}
$$

where $\lambda_{j}$ is the eigenvalue for the $j^{\text {th }} \mathrm{EOF}$; and $N$ is the degrees of freedom. When the difference between neighboring eigenvalues satisfied $\lambda_{j}-\lambda_{j+1} \geq e_{j}$, then the EOF modes represented by these two eigenvalues were statistically significant.

\section{Results and Discussion}

\section{Temporal variations of SST patterns}

The monthly mean SST and the SST anomalies in each of the four regions of the YS for each study year (2011, 2012 and 2013) are presented in Fig. 2 and Fig. 3, respectively. The monthly anomaly at a given pixel was calculated as the difference between the mean monthly SST minus the total mean SST for the entire study period of 36 months. The SST and the SST anomalies in each region both show similar monthly temporal patterns during the three study years.
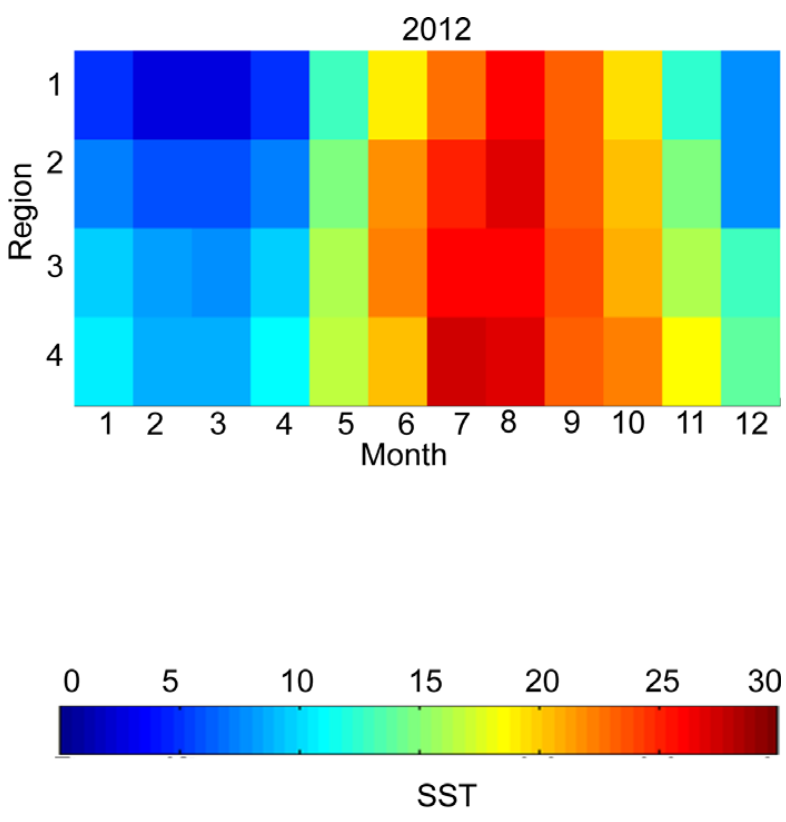

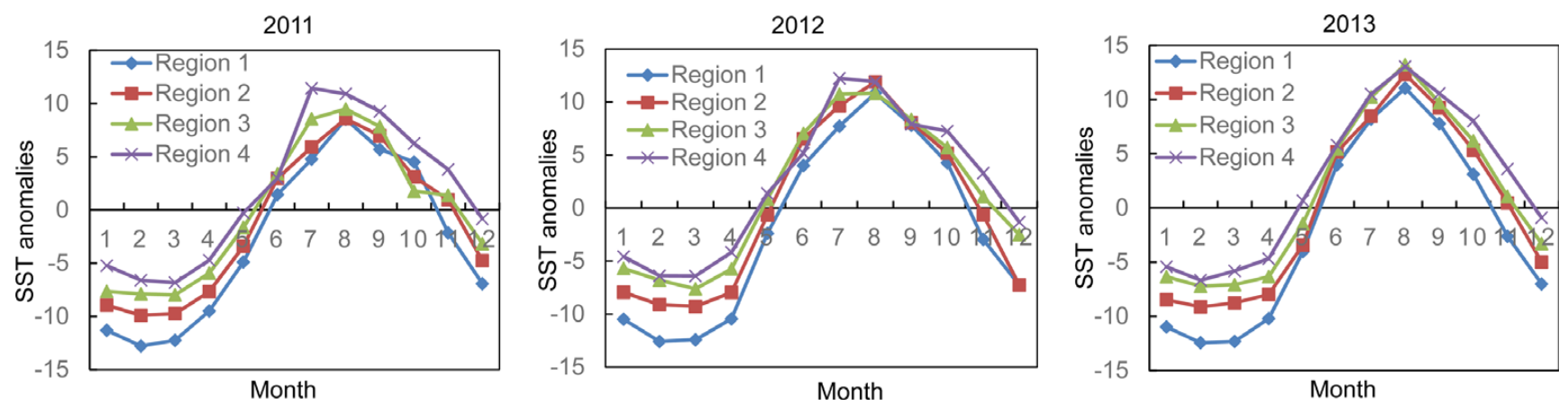

Fig. 3. Changes in monthly mean SST anomalies $\left({ }^{\circ} \mathrm{C}\right)$ in the four regions during three study years (2011-2013)

Table 1. Monthly SST $\left({ }^{\circ} \mathrm{C}\right)$ statistical characteristics for each of the three study years (2011-2013)

\begin{tabular}{cccccccccccccc}
\hline \hline & & \multicolumn{3}{c}{ The whole year } & \multicolumn{4}{c}{ Summer } & \multicolumn{4}{c}{ Winter } \\
\cline { 3 - 15 } & Mean & Max. & Min. & $C V$ & Mean & Max. & Min. & $C V$ & Mean & Max. & Min. & $C V$ \\
\hline \multirow{3}{*}{ Region 1 } & 2011 & 12.30 & 23.73 & 2.43 & 8.53 & 20.12 & 22.25 & 18.20 & 2.92 & 5.20 & 6.45 & 3.18 & 11.22 \\
& 2012 & 13.21 & 26.05 & 2.61 & 7.95 & 22.72 & 23.94 & 20.99 & 1.90 & 4.97 & 6.69 & 1.86 & 16.65 \\
& 2013 & 13.07 & 26.26 & 2.76 & 10.25 & 22.94 & 25.52 & 20.51 & 3.42 & 5.71 & 7.48 & 4.09 & 10.89 \\
\hline \multirow{3}{*}{ Region 2 } & 2011 & 13.87 & 23.78 & 5.30 & 4.76 & 21.02 & 22.16 & 19.71 & 1.87 & 7.93 & 9.58 & 4.94 & 7.53 \\
& 2012 & 15.07 & 27.10 & 5.92 & 5.18 & 24.55 & 25.93 & 22.33 & 2.64 & 6.91 & 9.49 & 3.33 & 9.50 \\
& 2013 & 15.05 & 27.53 & 6.07 & 4.69 & 23.85 & 25.13 & 21.24 & 2.91 & 8.02 & 8.19 & 5.94 & 4.56 \\
\hline \multirow{3}{*}{ Region 3 } & 2011 & 15.04 & 24.68 & 7.22 & 4.51 & 22.35 & 24.27 & 20.33 & 2.73 & 9.98 & 12.32 & 7.46 & 7.73 \\
& 2012 & 16.55 & 26.01 & 7.58 & 4.49 & 24.72 & 25.86 & 22.83 & 1.81 & 9.84 & 11.84 & 7.05 & 7.76 \\
& 2013 & 16.38 & 28.41 & 7.97 & 4.34 & 24.84 & 26.61 & 23.25 & 2.35 & 10.02 & 11.57 & 8.17 & 6.99 \\
\hline \multirow{3}{*}{ Region 4 } & 2011 & 16.87 & 26.62 & 8.37 & 5.31 & 23.63 & 25.62 & 22.17 & 2.31 & 11.27 & 15.21 & 8.00 & 10.45 \\
& 2012 & 17.39 & 27.44 & 8.79 & 5.87 & 24.97 & 26.25 & 23.34 & 2.16 & 10.72 & 13.48 & 8.54 & 7.99 \\
& 2013 & 17.59 & 28.24 & 8.52 & 4.18 & 24.98 & 26.07 & 23.91 & 1.58 & 11.73 & 15.14 & 9.72 & 10.87 \\
\hline
\end{tabular}

Maximum (Max), minimum (Min), coefficient of variation (CV)

Generally, for each year, the monthly mean SST increased from the northern to the southern regions. The SST ranged from $2.4^{\circ} \mathrm{C}$ to $28.4^{\circ} \mathrm{C}$, with seasonal cycles being strongest at the highest latitude (Region 1) and weakest at the lowest latitude (Region 4) (Table 1 and Fig. 2). The maximum SST values occurred between July and August while lower values occurred between February and March in each region. The highest 3-year SST $\left(\sim 28^{\circ} \mathrm{C}\right)$ was observed in Region 4 in August 2013, while the lowest 3-year SST $\left(\sim 2^{\circ} \mathrm{C}\right)$ was observed in Region 1 in February 2011. The seasonal variation in SST was affected mainly by the net sea surface heat flux; however, ocean circulation and mixing also influenced the temporal and spatial variations in SST (Zhai et al. 2010). For example, during winter, the SST in Region 4 was $\sim 11^{\circ} \mathrm{C}$ on average and was affected by the YSWC while, during summer, the SST in Region 2 and 3 were $\sim 23^{\circ} \mathrm{C}$ and $24^{\circ} \mathrm{C}$ due to the effects of the YSCWM, which were stronger during summer.

The monthly time series SST data also revealed a characteristic monthly cycle of the SST coefficient of variation $(\mathrm{CV})$, which was calculated as the ratio of standard deviation (STD) to mean SST and expressed as a percentage, in each of the four regions (Fig. 4). Most of the SST variability, characterized by the $C V$ displayed in Fig. 4, could be attributed to the annual cycle. The values were higher between January and March and were lower between July and October in most regions of the three study years. This annual cycle was the opposite of the seasonal cycle for the monthly SST variations. The STD of SST in each region showed similar variation trends to those of the $C V$ (Fig. 4). This was due to the efficient mixing of sea surface water layers in the YS by wind-induced and convective processes due to the presence of the YSCWM during the summer, which reduced variability; while in the absence of the YSCWM during the winter, the mixing was less efficient and variability was increased (Chu et al. 2005). For the entire study period, the mean SST $C V$ in Region 1 had the highest value $(8.9 \%)$ while values in the other three regions were all lower. This is consistent with the generally accepted view that variation during seasonal cycles would 

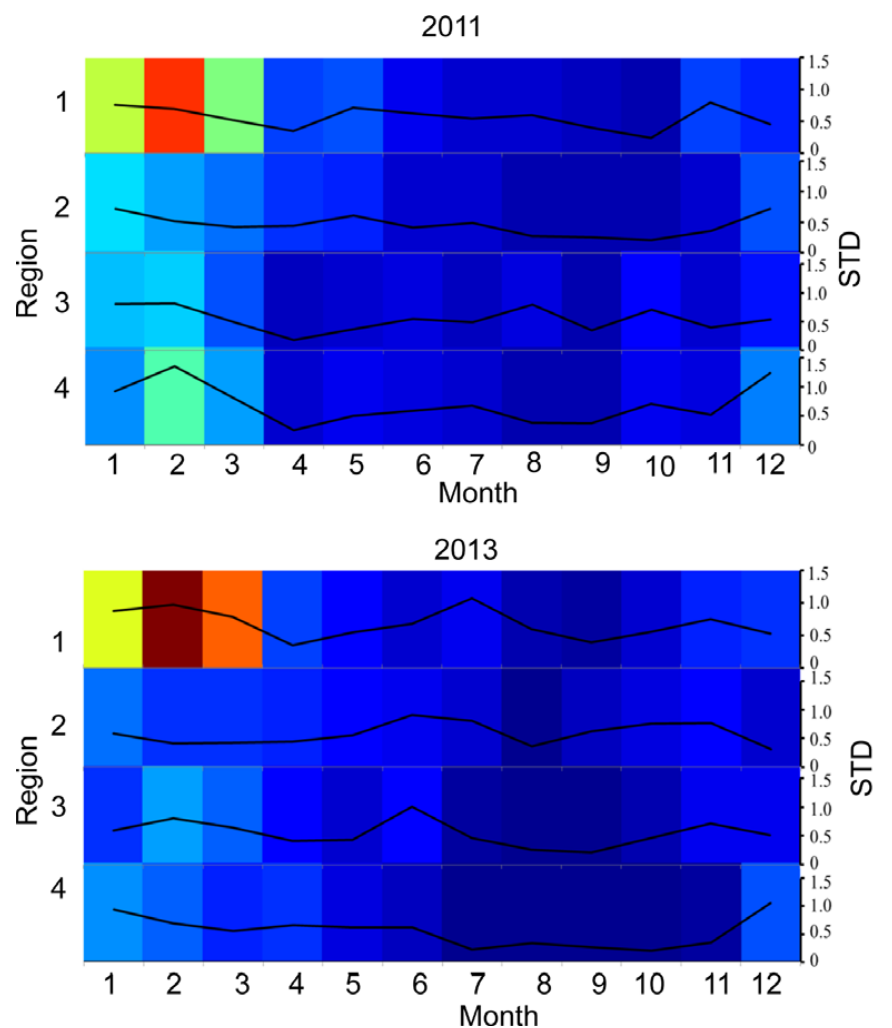
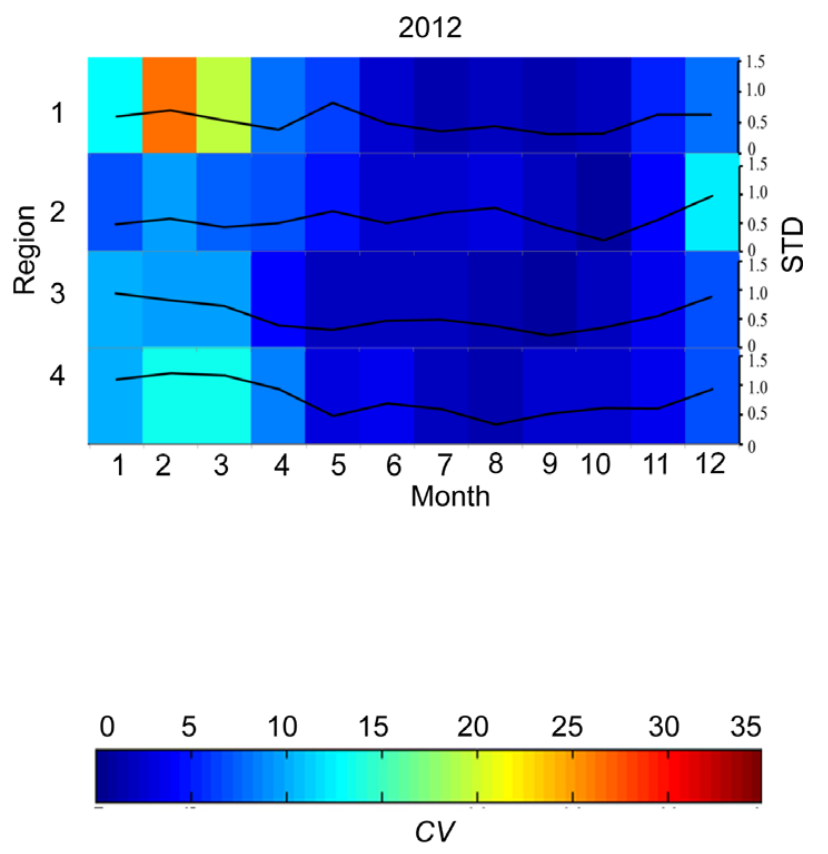

Fig. 4. Temporal distributions in the $C V$ and $\operatorname{STD}$ (black lines) of mean $\mathrm{SST}\left({ }^{\circ} \mathrm{C}\right)$ in the four regions during the three study years $(2011-$ 2013)

be stronger at the highest latitude (Region 1), where the seasonal fluctuations of the solar radiation were also greater than in regions closer to the equator (Esbensen and Kushnir 1981).

\section{Spatial variations in SST patterns}

The monthly SST in each year was temporally averaged to produce information about their respective seasonal (Fig. 5) and annual (Fig. 6) SST in the YS. The SST exhibited a sinusoidal seasonal cycle in which a persistent seasonal warming trend from winter to summer occurred in each year (Fig. 5). This demonstrated that there was a coherent pattern that was also shared by the variations in the monthly SST anomalies (Fig. 3). Spatially, the mean SST always followed the order of Region $1<$ Region $2<$ Region $3<$ Region 4 in each year. This was partly the result of the decreasing solar radiation with increasing latitude (Esbensen and Kushnir 1981). Another reason was that Region 2, Region 3 and Region 4 were all in the area affected by the YS water currents whereas Region 1 was closer to the north coastal water current. There were obvious differences in the temperatures between Region 1 and Region 4 in both the spring and winter; these differences were $5.3^{\circ} \mathrm{C}$ and $5.9^{\circ} \mathrm{C}$ respectively. In contrast, the difference was weak in the summer and fall between Region $1\left(2.6^{\circ} \mathrm{C}\right)$ and Region $4\left(3.8^{\circ} \mathrm{C}\right)$, since the YSWC in the south east of the YS begins to form in winter and diminishes during summer.

The spatial distributions of the annual SST during each of the three study years (2011-2013) are shown in Fig. 6. In 2011 , the SST in the YS ranged from $2.4^{\circ} \mathrm{C}$ to $26.6^{\circ} \mathrm{C}$ with a mean SST of $14.5^{\circ} \mathrm{C}$. In 2012 , the SST in most areas ranged from $2.6^{\circ} \mathrm{C}$ to $27.4^{\circ} \mathrm{C}$ with a mean of $15.6^{\circ} \mathrm{C}$. In 2013 , the SST ranged from $2.8^{\circ} \mathrm{C}$ to $28.4^{\circ} \mathrm{C}$ with a mean of $15.5^{\circ} \mathrm{C}$. In each year, the isotherms were generally parallel to the isobaths, running in the southwest-northeast direction. Three cold areas were evident, i.e., in the coastal waters to the west, east and north, which were influenced by the coastal water current. Two warm areas were also observed in the central and southeast YS that were related to the YS warm currents. There were no significant differences among the four regions $(p<$ 0.05 ) in any study year. However, the geographical distribution of SST was characterized by an obvious gradient whereby SST increased from the northern to the southern parts of the YS, with the 3-year mean SST increasing from about $12.9^{\circ} \mathrm{C}$ in Region 1 to $17.3^{\circ} \mathrm{C}$ in Region 4 . 

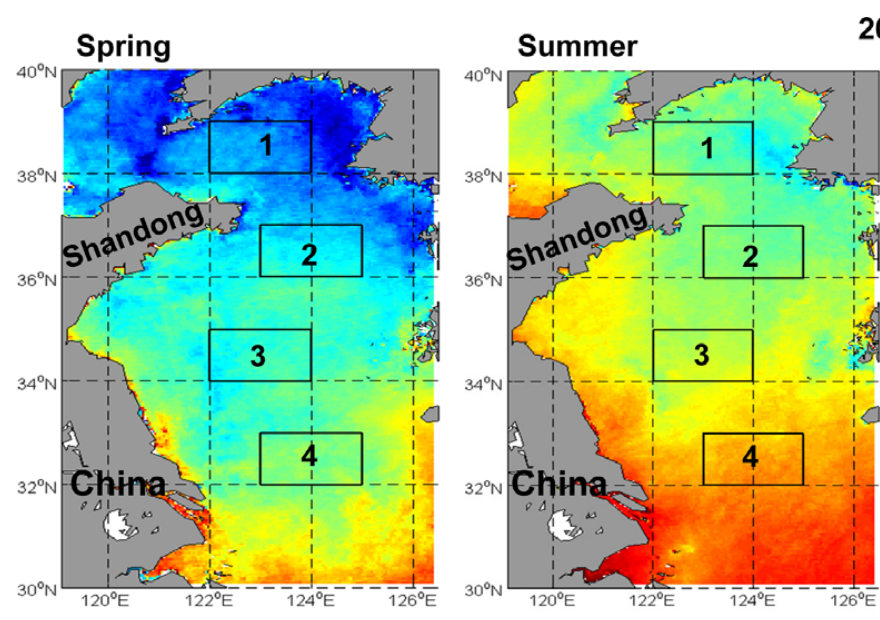

2011 Fall
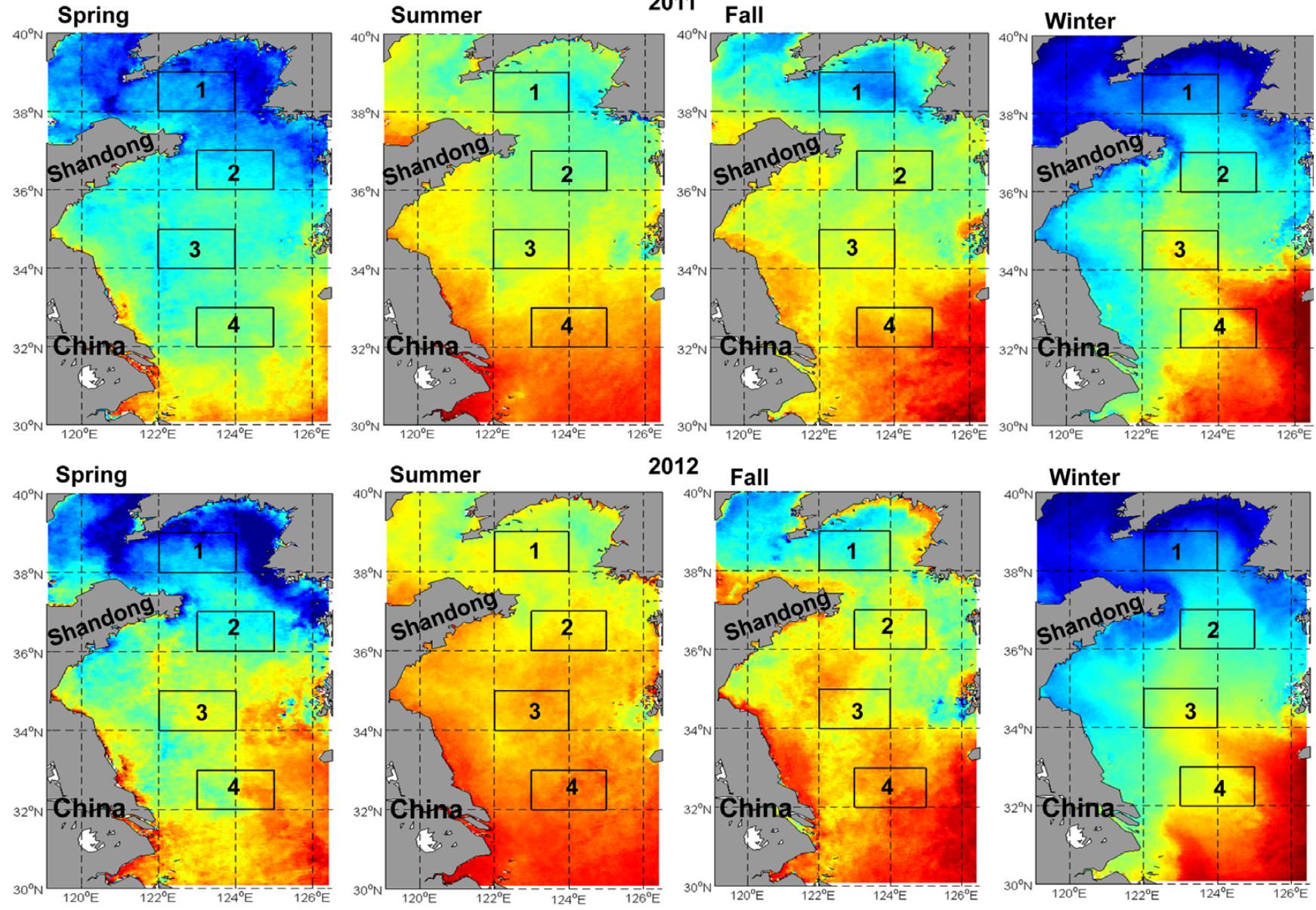

2012 Fall
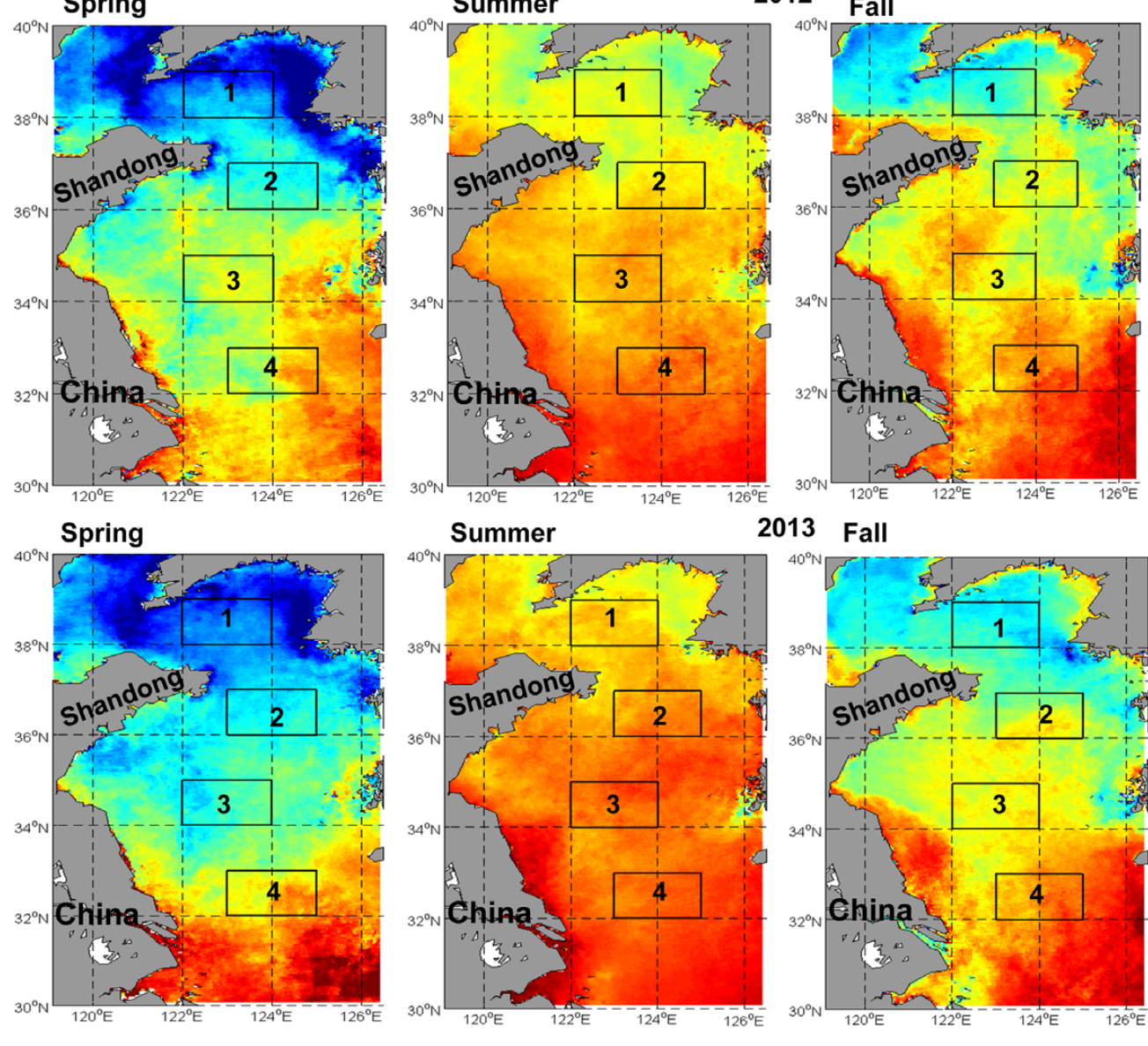

Winter

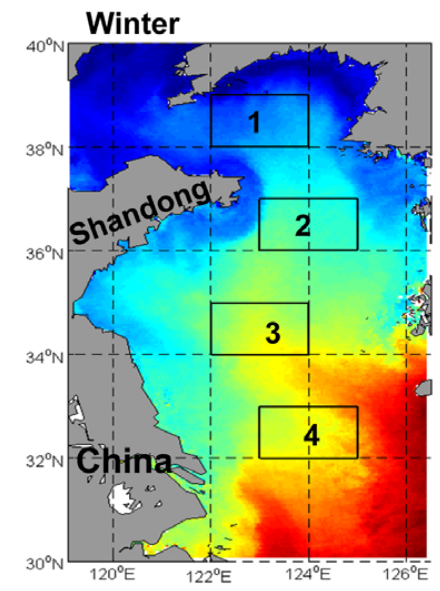

2013 Fall

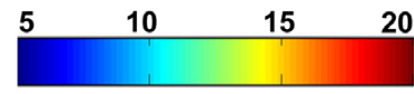

SST

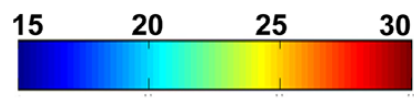

SST

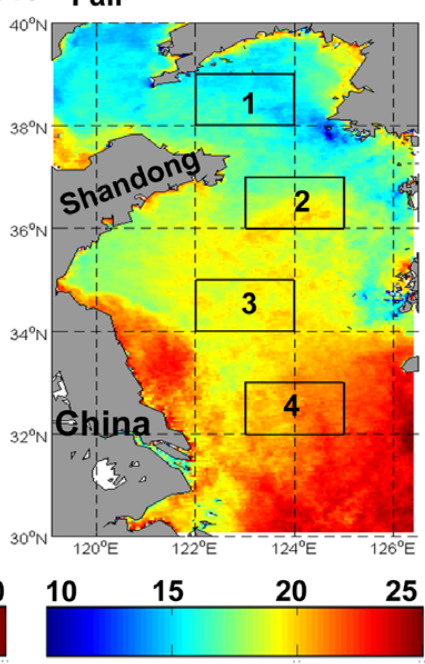

SST
Winter
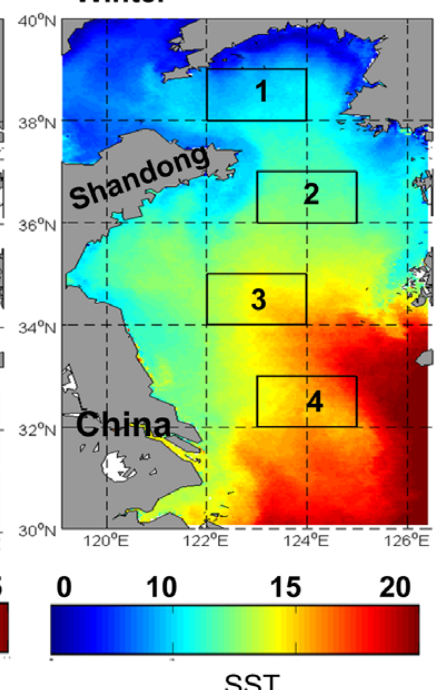

SST

Fig. 5. Spatial distributions of seasonal SST $\left({ }^{\circ} \mathrm{C}\right)$ in the three study years (2011-2013)

\section{Empirical orthogonal function (EOF) analysis of SST}

The variance contribution and cumulative variance of the first six EOF modes are presented in Table 2. The North test showed that only the first three modes passed the significance test in our study. Therefore, in this paper, only the first three modes were discussed. The EOF1 mode accounted for $56 \%$ of the total spatial SST variance (Table 2). The SST anomalies in the EOF1 mode for the entire study area were all positive 

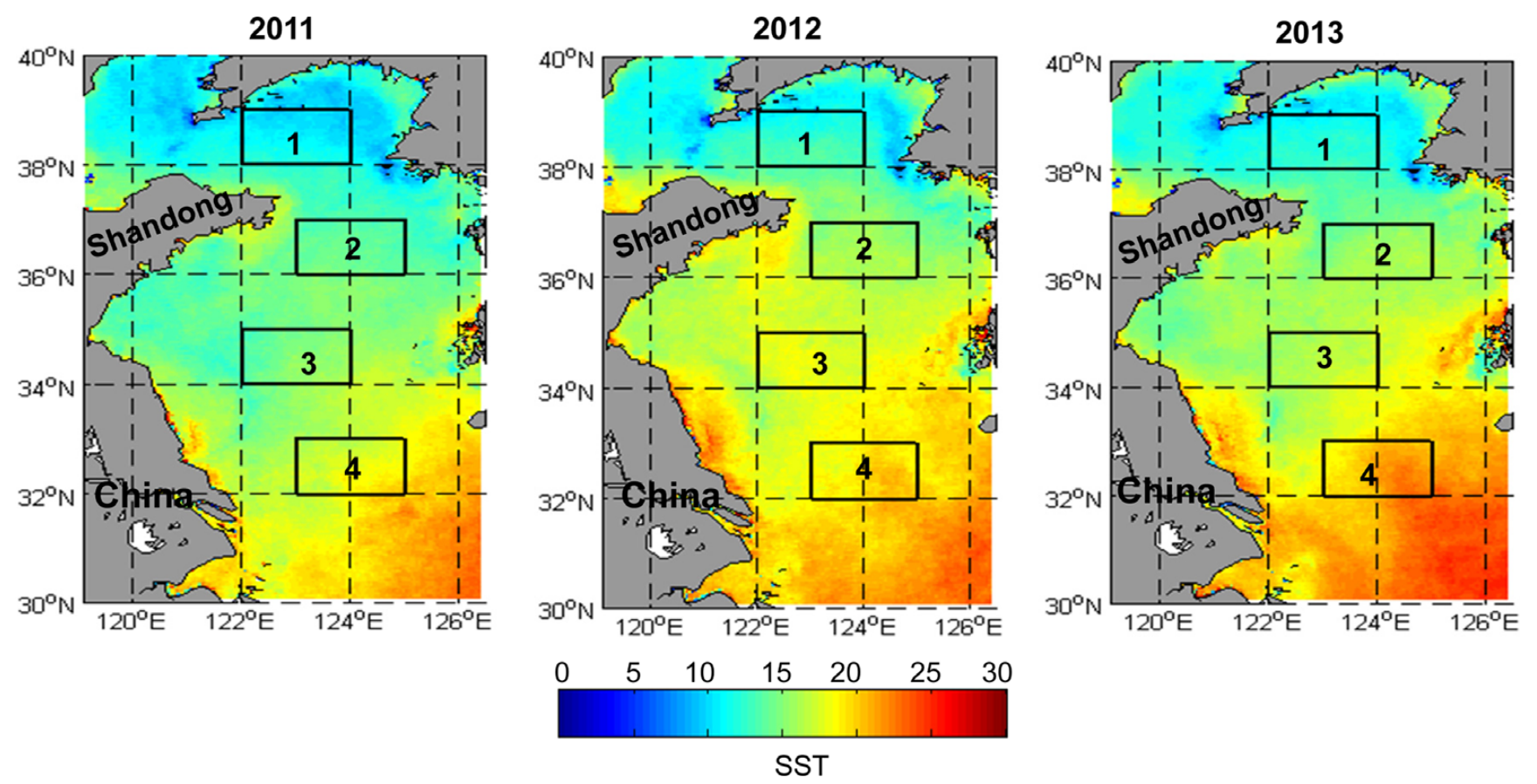

Fig. 6. Spatial distributions of annual SST $\left({ }^{\circ} \mathrm{C}\right)$ in the three study years (2011-2013)

Table 2. Variance contributions (\%) of the first six empirical orthogonal function (EOF) modes

\begin{tabular}{ccccccc}
\hline \hline EOF & EOF1 & EOF2 & EOF3 & EOF4 & EOF5 & EOF6 \\
\hline Variance contribution & 55.91 & 7.57 & 6.35 & 3.75 & 2.81 & 2.71 \\
Cumulative variance contribution rate & 55.91 & 63.48 & 69.83 & 73.58 & 76.39 & 79.10 \\
\hline
\end{tabular}
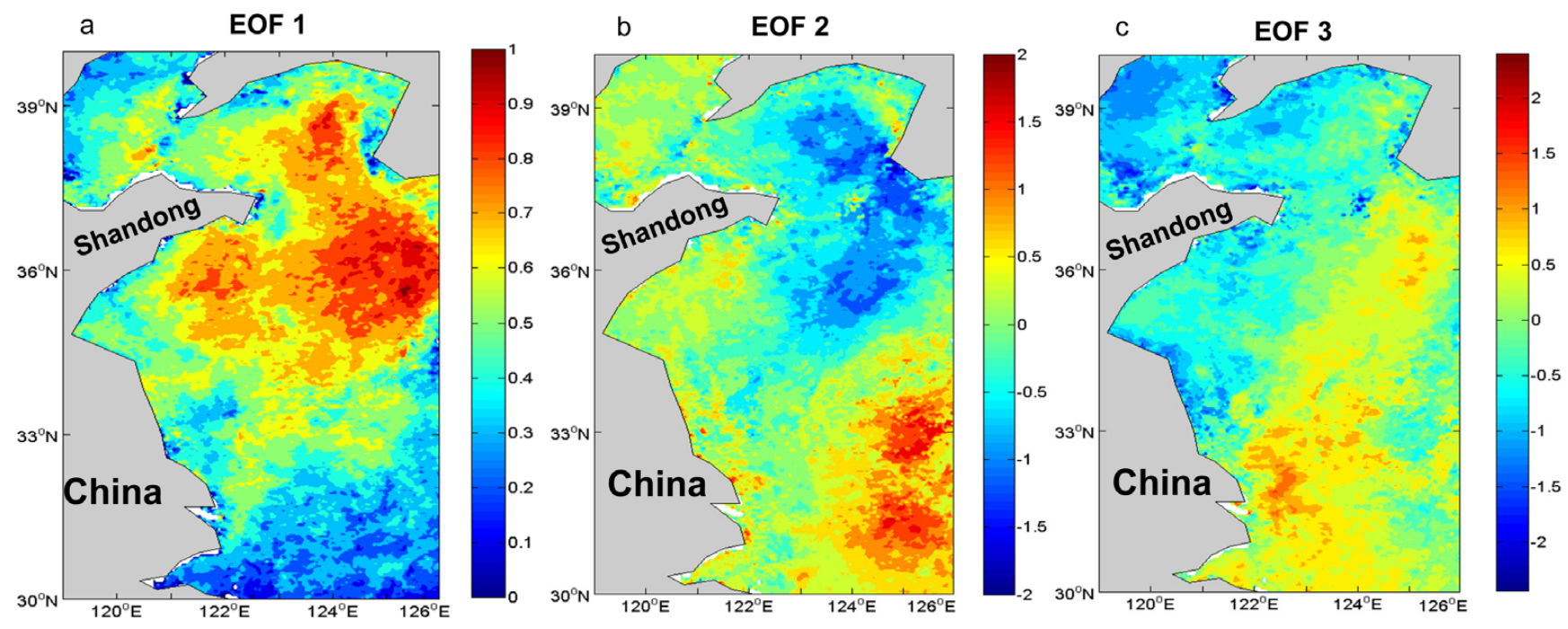

Fig. 7. EOF analysis of monthly SST anomalies $\left({ }^{\circ} \mathrm{C}\right)$

(Fig. 7a), but they were not uniformly distributed throughout the entire study area. These findings were consistent with those of previous studies carried out in the YS (Zeng et al. 2006; Wang et al. 2009; Park et al. 2015). The center of the
SST anomalies was located in an area with the geographical coordinates of about $35^{\circ}-37^{\circ} \mathrm{N}$ and $124^{\circ}-126^{\circ} \mathrm{E}$, which was mainly affected by the YS coastal waters. When the time coefficients were positive, it indicated that the SST increased in 
the entire study area; negative coefficients indicated that the SST decreased. In our study, the EOF1 time coefficients had positive values in the warm water seasons (August-October) and negative values during the cold water season (January-May) in years 2012-2013 (Fig. 8a). Negative values occurred in the warm season in the year of 2011, which suggested that the summer of 2011 was relatively cold as compared to the
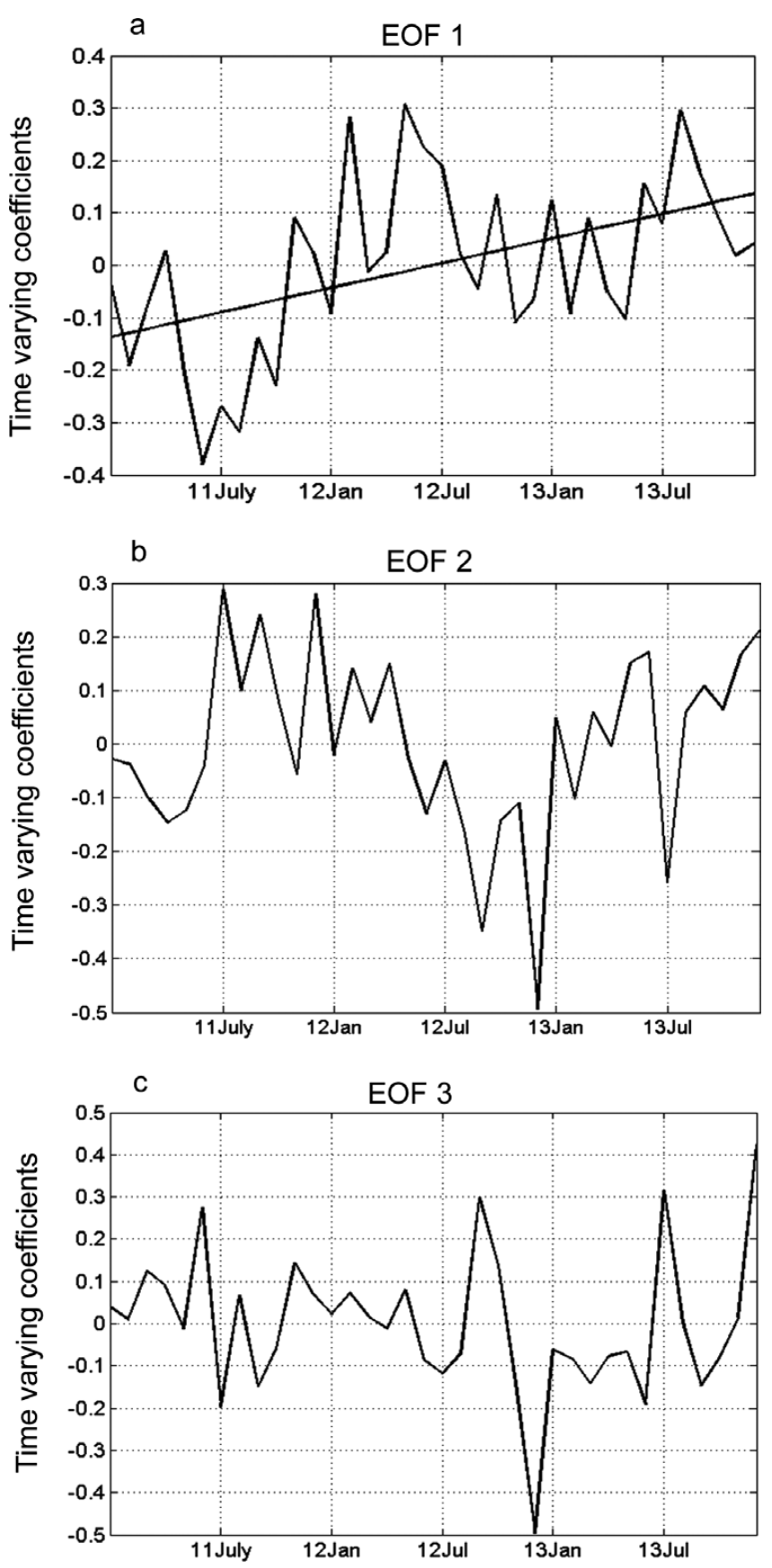

Fig. 8. Time-varying amplitude functions corresponding to Fig. 7 for three modes derived from the spatial variance EOF analysis summers in the years of 2012 and 2013. These results were consistent with that shown in Table 1. It indicated that the EOF1 mode was related to the SST inter-annual variations. The signal reflected that the EOF1 mode was not only influenced by the solar shortwave radiation energy and by the air temperature at the sea surface, but was also probably affected by the weather conditions (Park et al. 2015). The time coefficient of the EOF1 mode demonstrated the warming signal (Fig. 8a). This finding was consistent with earlier results published by Park et al. (2015). Park et al. (2015) indicated that there was a warming trend in the years 19812009. Our study focused on the years 2011-2013, which was a much shorter time series than that of Park et al. (2015). Consequently, we could not conclude that the SST in the YS had continued to increase from 1981 until 2013. More recent datasets should be used for further investigations. The STD calculated from the 3-year time series of SST is presented in Fig. 9. and is similar to the eigenvector map of the EOF1 mode presented in Fig. $7 \mathrm{a}$. The highest STD value $\left(\sim 1.2^{\circ} \mathrm{C}\right)$ occurred in an area bounded by $35-37^{\circ} \mathrm{N}$ and $124-126^{\circ} \mathrm{E}$.

The EOF 2 mode (accounting for $8 \%$ of the total variance) presented a feature that had a more north-south orientation (Fig. 7b). There was an opposite variability between the waters in the southeast, which were closer to the warm currents and

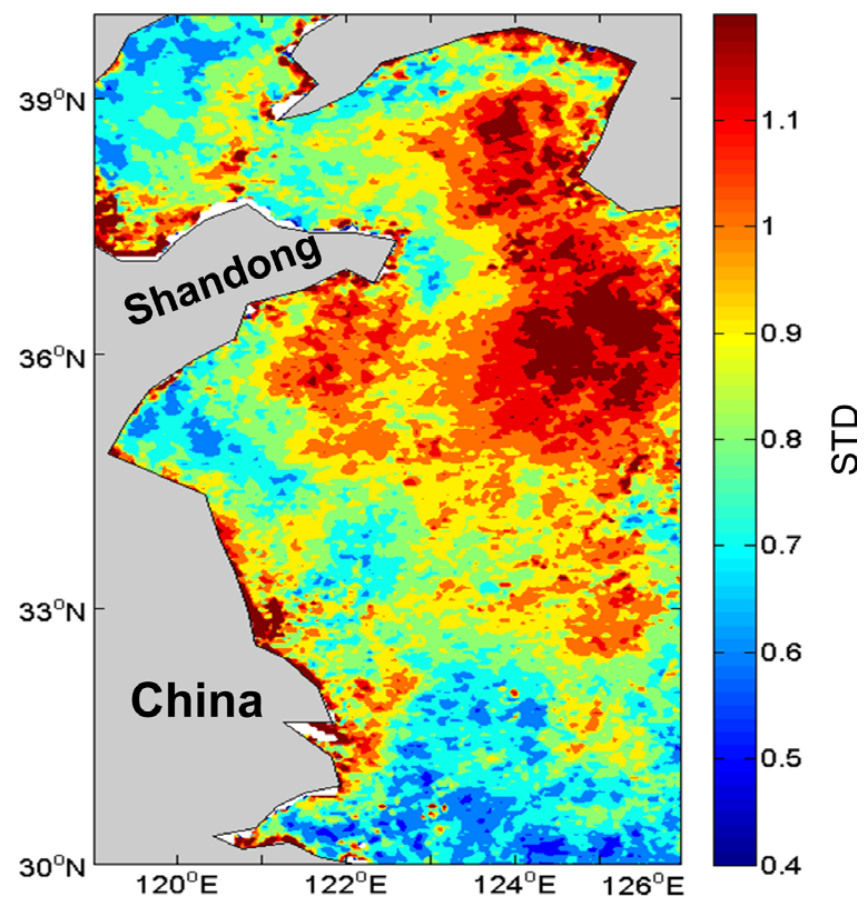

Fig. 9. Annual mean STD of SST $\left({ }^{\circ} \mathrm{C}\right)$ over the three study years (2011-2013) 
that exhibited a positive variation in SST, and a negative variation in the central waters; i.e., indicating that the two regions had opposing trends. The EOF2 mode could be explained by the influences of the YSWC in the southeast and of the YSCWM in the central waters of the YS. The time coefficients were positive, which indicated an increase in SST in the southeast area and a decrease in the central area of the YS. Conversely, when the time coefficients were negative, it indicated a decrease in SST in the southeast area and an increase in the central area (Fig. 8b).

The SST variations in the EOF3 mode (accounting for $6 \%$ of the total variance) alternated with positive and negative values occurring in the spatial pattern (Fig. 7c). The positive values occurred in the southern YS, while the negative values occurred in the northern YS. The spatial distribution of the EOF3 mode was similar to the SST presented in Fig. 10. The time coefficients exhibited greater inter-annual variation than they did for the seasonal cycles. The EOF3 mode could be explained by the influence of the sea floor topography. The time coefficient of the EOF3 mode showed high positive values in June/2011, September/2012, July/2013 and December/2013 (Fig. 8c), which were in contrast to the spatial distribution of the EOF3 in the northern YS. Probably in the summer, the YS experienced cooling events in the coastal

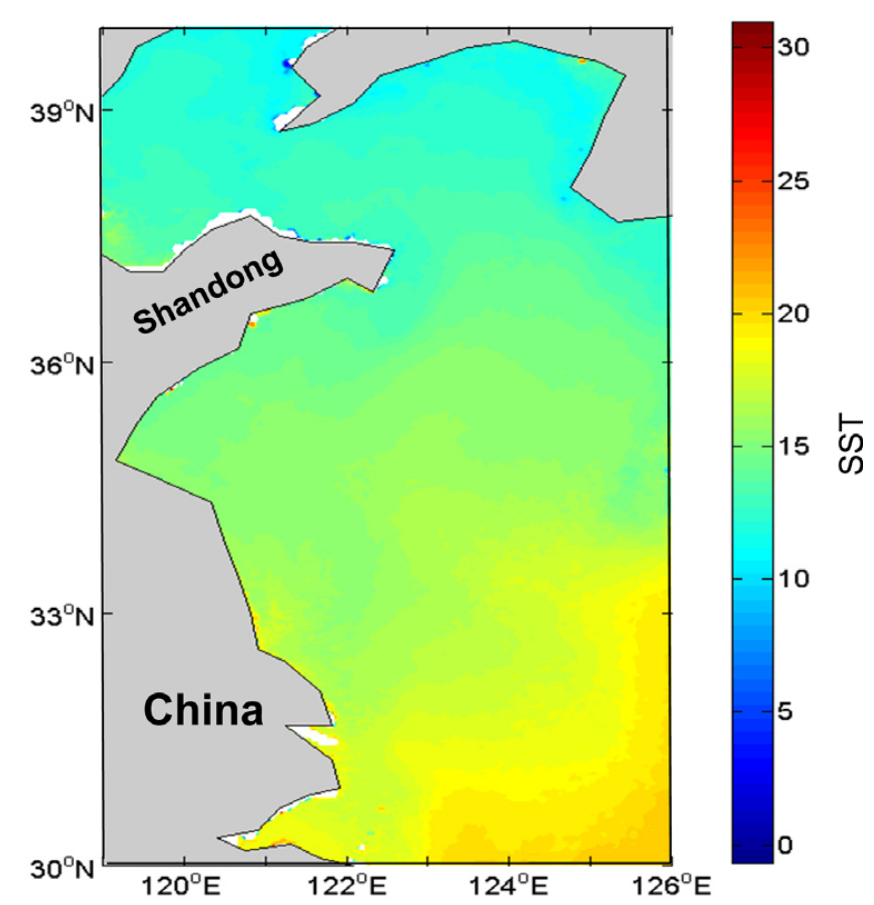

Fig. 10. Annual mean SST $\left({ }^{\circ} \mathrm{C}\right)$ over the three study years $(2011-$ 2013) waters of the northern YS. The SST anomalies exhibited larger seasonal variations in the shallower waters than those in the deeper waters. Since the coastal water had a low thermal capacity, the SST was easily changed in these areas by the weather conditions such as the occurrence of monsoon rains and atmospheric oscillations, etc.

\section{Conclusion}

In this study, MODIS SST datasets were used to study the detailed heterogeneity of SST by dividing the YS into four geographical regions. The SST in the region exhibited similar monthly temporal patterns in the three study years (2011, 2012 and 2013). The seasonal cycles showed the general trend that it was stronger at higher latitude (Region 1) and weaker at lower latitude (Region 4). Spatially, the maximum thermal difference between higher latitude (Region 1) and lower latitude (Region 4) was unequal and was larger in summer and winter, mostly because of the influence of the physical environments. Close to Region 4 the SST was mainly affected by the YSWC, which was stronger in winter than in summer. The spatial distribution of annual SST had isotherms that were generally parallel to the isobaths, which ran in a southwest-northeast direction. Although there were no significant differences among the four regions $(p<0.05)$ in any year, the geographical distribution of SST was characterized by an obvious gradient whereby temperatures decreased from the southern to the northern parts of the YS.

The remarkable feature from EOF1 was a manifest distinction in the spatial patterns of the eigenvector map, which was similar to the overall SST STD pattern in the YS. The center of the SST anomalies was located in an area with the geographical coordinates of about $35^{\circ}-37^{\circ} \mathrm{N}$ and $124^{\circ}-126^{\circ} \mathrm{E}$. The time coefficient of the EOF1 increased during the study period. The EOF2 mode accounted for $8 \%$ of the total variance, and indicated the importance of the features of the different currents occurring in the YS. The EOF3 mode accounted for $6 \%$ of the total variance and indicated the influence of the sea floor topography. The results of this study can improve our understanding of spatio-temporal variability in SST in the YS. In future studies, datasets with more combined sources collected over longer time series should be used in order to more accurately determine the seasonal cycles and the interannual variability in the YS. 


\section{Acknowledgements}

The authors are very grateful to two anonymous reviewers for their helpful comments. This study was supported by the National Science Foundation of China (41206166); The Science and Technology Development Plan Project of Weihai (2014DXGJ36); The State Key Laboratory of Tropical Oceanography, South China Sea Institute of Oceanology, Chinese Academy of Sciences (LTO1608); The Natural Science Foundation of Shandong Province, China (ZR2010DQ019).

\section{References}

Alvarez F, Pan SQ (2016) Predicting coastal morphological changes with empirical orthogonal function method. Water Sci Eng 9(1): $14-20$

Brown OB, Minnett PJ (1999) MODIS infrared sea surface temperature algorithm-algorithm theoretical basis document (version 2). University of Miami, Miami, $98 \mathrm{p}$

Chu Peter, Chen YC, Kuninaka A (2005) Seasonal variability of the Yellow Sea/East China sea surface fluxes and thermohaline structure. Adv Atmos Sci 22(1):1-20

Esbensen SK, Kushnir J (1981) The heat budget of the global ocean: An atlas based on estimates from surface marine observations. Oregon State University, Corvallis, Oregon State University Climate Research Institute Repopt 29, 271 p

Ho CB, Wang YX, Lei ZY, Xu S (1959) A preliminary study of the formation of Yellow Sea Cold Water Mass and its properties. Oceanol Limnol Sin 2(1):11-15 (in Chinese)

$\mathrm{Hu}$ W, Si BC (2016) Estimating spatially distributed soil water content at small watershed scales based on decomposition of temporal anomaly and time stability analysis. Hydrol Earth Syst Sci 20:571-587

Kelly KA (1988) Comment on 'EOF analysis of Advanced Very High Resolution Radiometer surface temperature patterns in Santa Barbara Channel' by Gary S. E. Lagerloef and Robert L. Bernstein. J Geophys Res 93:15753-15754

Lagerloef GSE, Bernstein RL (1988) Empirical orthogonal function analysis of Advanced Very High Resolution Radiometer surface temperature pattern in Santa Barbara Channel. J Geophys Res 93:6863-6873

Lie H-J, Cho H-C, Lee S (2009) Tongue-shaped frontal structure and warm water intrusion in the southern Yellow Sea in winter. $\mathrm{J}$ Geophys Res 114(C1):362-370

Lin C, Ning X, Su J, Lin Y, Xu B (2005) Environmental changes and the responses of the ecosystems of the Yellow Sea during 1976-2000. J Marine Syst 55:223-234

Mei X, Li RH, Zhang XH, Liu QS, Liu JX, Wang ZB, Lan XH, Liu J, Sun RT (2016) Evolution of the Yellow Sea Warm Current and the Yellow Sea Cold Water Mass since the Middle Pleistocene. Palaeogeogr Palaeoclimatol Palaeoecol 442:48-60
North GR, Bell TL, Cahalan RF, Moeng FJ (1982) Sampling errors in the estimation of empirical orthogonal functions. Mon Weather Rev 110(7):699-706

Park KA, Lee EY, Chang E, Hong SW (2015) Spatial and temporal variability of sea surface temperature and warming trend in the Yellow Sea. J Marine Syst 143:24-38

Shi W, Wang M (2012) Satellite views of the Bohai Sea, Yellow Sea, and East China Sea. Prog Oceanogr 104:30-45

Teague WJ, Jacobs GA (2000) Current observations on the development of the Yellow Sea Warm Current. J Geophys Res 105(C2): 3401-3411

Tseng C, Lin C, Chen S, Shyu C (2000) Temporal and spatial variations of sea surface temperature in the East China Sea. Cont Shelf Res 20(4):373-387

Uda M (1934) The results of simultaneous oceanographical investigations in the Japan Sea and its adjacent waters in May and June 1932. J Imp Fish Exp St 5:138-190 (in Japanese)

Uda M(1936) Results of simultaneous oceanographical investigations in the Japan Sea and its adjacent waters during October and November 1933. J Imp Fish Exp St 7:91-151(in Japanese)

Wang HW, Yu F, Lu LG, Diao XY, Guo JS (2009) Characteristics of spatial and interannual variation in the Yellow Sea Warm Current area and winter. Adv Mar Sci 27(2):140-148 (in Chinese)

Wei H, Shi J, Lu Y, Peng Y (2010) Interannual and long-term hydrographic changes in the Yellow Sea during 1977-1998. Deep-Sea Res Pt II 57:1025-1034

Wei QS, Li XS, Wang BD, Fu MZ, Ge RF, Yu ZG (2016) Seasonally chemical hydrology and ecological responses in frontal zone of the central southern Yellow Sea. J Sea Res 112:1-12

Xu M, Liu QH, Zhang ZN, Liu XS (2016) Response of free-living marine nematodes to the southern Yellow Sea Cold Water Mass. Mar Pollut Bull 105:58-64

Yeh SW, Kim CH (2010) Recent warming in the Yellow/East China Sea during winter and the associated atmospheric circulation. Cont Shelf Res 30(13):1428-1434.

Yu F, Zhang ZX, Diao XY, Guo JS (2010) Observational evidence of the Yellow Sea Warm Current. Chin J Oceanol Limn 28(3): 677-683

Yu F, Zhang ZX, Diao XY, Guo JS, Tang YX (2006) Analysis of evolution of the Huang hai Sea cold water mass and its relationship with adjacent water masses. Acta Oceanol Sin 28(5):26-34 (in Chinese)

Zeng GE, Lian SM, Cheng XH, Hua ZL, Qi YQ (2006) EOF analysis of intra seasonal variabilities of SST in the east China Sea and Yellow Sea. Adv Mar Sci 24(2):146-155 (in Chinese)

Zhai L, Platt T, Tang C, Sathyendranath S, Fuentes-Yaco C (2010) Seasonal and geographic variations in phytoplankton losses from the mixed layer on the Northwest Atlantic Shelf. J Mar Syst 80:36-46

Zhang SW, Wang QY, Lü Y, Cui H, Yuan YL (2008) Observation of the seasonal evolution of the Yellow Sea Cold Water Mass in 1996-1998. Cont Shelf Res 28:442-457 